\title{
Clinical Characteristics and Outcomes of Patients with COVID-19 Infection: The Results of the SARS-RAS Study of the Italian Society of Hypertension
}

\author{
Costantino Mancusi ${ }^{1,2} \cdot$ Guido Grassi $^{3}(\mathbb{D})$. Claudio Borghi ${ }^{4}\left([) \cdot\right.$ Claudio Ferri $^{5} \cdot$ Maria Lorenza Muiesan $^{6}$. \\ Massimo Volpe $\mathrm{e}^{7,8}$. Guido laccarino ${ }^{1,2}$. . SARS-RAS Investigator Group
}

Received: 12 November 2020 / Accepted: 22 December 2020

(c) The Author(s) 2021

\begin{abstract}
The COVID-19 infection has rapidly spread around the world and a second wave is sweeping in many countries. Different clinical and epidemiological aspects characterize the disease and their understanding is necessary to better face the management of the pandemic in progress. The Italian society of arterial hypertension with the SARS-RAS study has contributed significantly to the knowledge of the interaction between inhibition of the renin-angiotensin system and COVID-19 infection. Furthermore, the study results help to understand some of the main aspects related to mortality and morbidity deriving from the infection through a multicentre analysis throughout the national territory.
\end{abstract}

keywords Anti-hypertensive therapy $\cdot$ Sars-Cov $2 \cdot$ Frailty $\cdot$ Comorbidities $\cdot$ Sex-differences

\section{Introduction}

Starting from February 2020, a new coronavirus (COVID19) infection has spread all over the world, starting from Wuhan in China. The infection was highly transmissible

The members of the SARS-RAS Investigator Group are listed in Acknowledgements.

\section{Guido Iaccarino}

guiaccar@unina.it

Guido Grassi

guido.grassi@unimib.it

Claudio Borghi

Claudio.borghi@unibo.it

Claudio Ferri

claudio.ferri@univaq.it

Maria Lorenza Muiesan

marialorenza.muiesan@unibs.it

Massimo Volpe

massimo.volpe@uniroma1.it

1 Department of Advanced Biomedical Sciences, Federico II University of Naples, Via Panisini 5, 80138 Naples, Italy

2 Interdepartmental Research Center on Hypertension and Associated Conditions, Federico II University, Naples, Italy and the numbers of COVID-19 have now reached more than 43 million patients and over 1,000,000 deaths. The COVID-19 receptor exhibits affinity domains with the type 2 angiotensin-converting enzyme (ACE2), and then uses the ACE2 receptor for cell entry [1]. On March 11, The Lancet Respiratory Medicine published a letter by Fang et al., raising and spreading alarm among physicians and patients.

3 Department of Medicine and Surgery, University of Milano-Bicocca, Milan, Italy

4 Department of Medicine and Surgery Sciences, Alma Mater Studiorum University of Bologna, Bologna, Italy

5 Department of Clinical Medicine, Public Health, Life and Environment Sciences, University of L'Aquila, L'Aquila, Italy

6 Department of Clinical and Experimental Sciences, University of Brescia, Medicina 2, ASST Spedali Civili Brescia, Brescia, Italy

7 Clinical and Molecular Medicine Department, Sapienza University Sant'Andrea Hospital, Rome, Italy

8 IRCCS Neuromed, Pozzilli, IS, Italy 
Authors assumed that therapy with the renin-angiotensin system (RAS), i.e. ACE-Inhibitors (ACEi) or Angiotensin receptor blockers (ARBs) can facilitate COVID-19 infection and even increase the risk of developing severe and fatal SARS-CoV2. Given the fact that hypertensive and diabetic patients are most often treated with those medications, this news had a great wake on media and socials [2], leading to social alarm among chronic patients receiving this class of drugs. The reaction of many scientific societies around the world including the Italian Society of Hypertension was to provide reassuring statements of lack of scientific evidence to support the detrimental role of ACE/ARBS, waiting for scientific data exploring the deep analysis and understanding of the complex phenomenon of COVID-19 infection with specific regards of the safety of ACE-I or ARBs [3] and give practical advices for the cardiovascular prevention during this pandemic [4]. Up to now, the whole scientific community is actively involved in hectic activities regarding all aspects of disease pathogenesis, epidemiology, and treatment. The number of scientific reports about COVID-19 has raised from January to date to more than 67,000 (Source: Pubmed, 20/10/2020).

In this context, the Italian Society of Hypertension promoted the SARS-RAS study, a multicenter, nationwide survey in Italy with the primary objective to verify whether drugs that interact with the renin-angiotensin system such as ACEi and ARBs are related to COVID-19 severe outcomes.

\section{The SARS-RAS Study}

The SARS-RAS was a cross-sectional, multicenter, observational study conducted in 28 hospitals and centers in 13 regions in Italy, and the contribution of the centers reflected the geographical distribution of the disease, most of the patients being located in Northern regions, especially Lombardy, compared to Southern regions. The patients' cohort included 2446 patients aged 18-101 years with confirmed COVID-19, according to World Health Organization interim guidance [5]. The observation period started on March 9 and the last entry is on September 7. The SARS-RAS study is registered in Clinicaltrials.gov at the accession number NCT04331574.

An online questionnaire was distributed among the centers to collect reviewed epidemiological, clinical, and outcomes data from hospital emergency rooms, regular and intensive care wards. The questionnaire collected information on pseudonymized patients including anthropometric, anamnestic, and clinical features. We also collected pharmacological regimens with RAS inhibitors (ACEi, ARBs, and other antihypertensive drugs and the degree of the severity of COVID-19 [6]. Information regarding the outcomes of the disease if available were also collected. The electronic data was transmitted with the modern cryptography systems over the web and stored in a locked, password-protected computer. COVID-19 diagnosis was confirmed in all patients by RT-PCR performed on nasopharyngeal or throat swab samples [7] in each center by the designated Institutions.

\section{RAS Inhibitors and COVID-19 Infection}

Interaction with membrane-bound angiotensin-converting enzyme 2 (ACE2) on the respiratory epithelium represents the main mechanism for COVID-19 infection. ACE2 shares analogies for the ACE, from which differs being an aminopeptidase rather than a carboxyl peptidase. Its role in the production of angiotensin II and therefore activation of the RAS and its neurohormonal pathways is marginal [8]; nevertheless, treatment with RAS inhibitors can increase the cell surface exposure of ACE2. This evidence poses the basis for the hypothesis that ACEi or ARBs might increase the risk of COVID-19 infection. On the other hand, animal models of acute lung injury have demonstrated that pretreatment with ACE inhibitors, ARBs, or beta-blockers may reduce the extent of experimentally induced lung injury and improve outcomes, an effect mediated by inhibition of the RAAS [9]. Thus, others have hypothesized that these medications could theoretically be beneficial, reducing the risk of severe disease among patients with Covid-19 [10]. However, up to now, there is no evidence that the possibility of harmful effects of ACEi and ARBs is more than mere speculation [11], despite enormously amplified by media and social, forcing the major international societies to issue position statements, though with different intensity [12]. The Italian Society of Hypertension therefore prompted the SARS-RAS study to scientifically answer these questions. The results of the study are comprehensively presented in table 1 .

\section{Hypertension Does Not Accelerate COVID-19}

In the SARS-RAS study, we have firstly analyzed information from 1500 patients diagnosed with COVID-19 (male, $64.1 \%$; $66 \pm 0.4$ years) to analyze the impact of antihypertensive therapy on mortality from COVID-19 [13]. ACE inhibitors, diuretics, and $\beta$-blockers were more frequently used in non-survivors than in survivors. After correction by multivariate analysis, only age, diabetes mellitus, chronic obstructive pulmonary disease, and chronic kidney disease but not hypertension predicted mortality with no effect of ACE inhibitors or ARBs. Our data do not support a 
Table 1 Synoptic review of the published findings of the SARS-RAS study of the Italian Society of Hypertension

\begin{tabular}{|c|c|c|c|c|}
\hline Objective & $\begin{array}{l}\text { Sample } \\
\text { size }\end{array}$ & Main findings & Journals & Reference \# \\
\hline Hypertension causes COVID-19 & 1590 & $\begin{array}{l}\text { No association between hypertensive status } \\
\text { and COVID-19 }\end{array}$ & Hypertension & [13] \\
\hline Determinants of death outcome in COVID-19 & 1590 & $\begin{array}{l}\text { Age and multimorbidities determine death } \\
\text { during COVID-19 }\end{array}$ & Hypertension & [13] \\
\hline Determinants of ICU acces in COVID patients & 2378 & $\begin{array}{l}\text { Male sex almost doubles the risk of ICU. Dif- } \\
\text { ferent ages and morbidities determine male } \\
\text { and female admission in ICU }\end{array}$ & PLOS One & {$[24]$} \\
\hline Determinants of healing of COVID-19 patients & 2460 & $\begin{array}{l}\text { Young patients without morbidities heal bet- } \\
\text { ter than older multimorbid patients }\end{array}$ & Journal of Hypertension & [29] \\
\hline $\begin{array}{l}\text { ACE inhibitors and ARBs protect from } \\
\text { COVID-19 }\end{array}$ & 2460 & $\begin{array}{l}\text { No effects of ACE and ARBs on the out- } \\
\text { comes of COVID-19 }\end{array}$ & Journal of Hypertension & [29] \\
\hline Other drugs interfering with COVID-19 & 2460 & $\begin{array}{l}\text { Oral anticoagulants for thromboembolic } \\
\text { events prophylaxis ameliorate COVID- } 19 \\
\text { prognosis }\end{array}$ & Submitted & N/A \\
\hline
\end{tabular}

significant interference of hypertension and antihypertensive therapy on COVID-19 lethality. Different reports from all over the world have confirmed our results demonstrating that previous treatment with medications acting on the RAAS was not associated with a higher risk of testing positive for Covid-19 and neither substantially higher risk (by $\geq 10$ percentage points) of severe Covid-19 infection [14-16]. Some recent evidence also suggests that the use of ACE inhibitors or ARBs in patients with COVID-19 infection is associated with a lower inflammatory burden and less severe disease supporting the use of ARBs/ACE inhibitors in patients with COVID-19 and preexisting hypertension [17], 18].

\section{Determinants of Mortality Among COVID-19 Patients}

The clinical presentation of COVID-19 can vary differently from patient to patient, ranging from completely asymptomatic to severe and death. Data from the SARS-RAS study have demonstrated that age and comorbidities play a major role in determining death in patients with COVID19 infection [13]. In particular, when calculating the death rate according to age organized by decades, this appears to be stably below 5\% up to the 6th decade. Above that limit, the death rate stably increases per each year [3] (Fig. 1a). To measure the impact of multimorbidity, we used a frailty index, the Charlson Comorbidity Index, which is used by geriatricians to predict 10 years of mortality among community-dwelling older patients. This index cumulates older age and presence of multimorbidities; interestingly, Charlson Comorbidity Index can predict COVID-19 mortality with an exponential increase in the odds ratio by each point of score. This index is a useful tool to identify patients at higher risk of mortality and thus requiring close clinical monitoring in case of COVID-19 infection. Interestingly, this index can be also used to stratify the general population to identify subjects at higher risk of worse outcome in the case of COVID19, which can be the object of more intense prophylactic measures and treatment. Our results are in line with current evidence from other cross-sectional and prospective studies [19-21]. Other recent findings suggest that frailty increases the risk of mortality, even after accounting for age and other known comorbidities linked to COVID-19 [22].

\section{Determinants of Clinical Severity Among COVID-19 Patients}

Admission to the intensive care unit (ICU) is the main reason for concern during the COVID-19 pandemic, due to the limited capability of all national health care systems. Recent metanalysis on the rate of intensive care unit admission and outcomes among patients with coronavirus showed that the rate of ICU admission was $32 \%$ and that the pooled prevalence of mortality in patients with coronavirus disease in ICU was 39\% [23]. Opposite to what was observed for the death outcome, the rate of ICU access steadily increased up to the 6th decade; thereafter, it remained stable above $10 \%$ (Fig. 1b). Sex played a major role in COVID-19 infection and outcomes. Data from the SARS-RAS study on 2378 patients with confirmed COVID-19 infection shower that gender is the primary determinant of ICU admission with male sex exhibiting almost double risk of ICU admission [24]. Again, multimorbidity and older age cause admission in ICU, but women present with almost 10 years older age and different comorbidities (Heart failure and obesity) than man (Obesity, chronic Kidney disease and hypertension) 


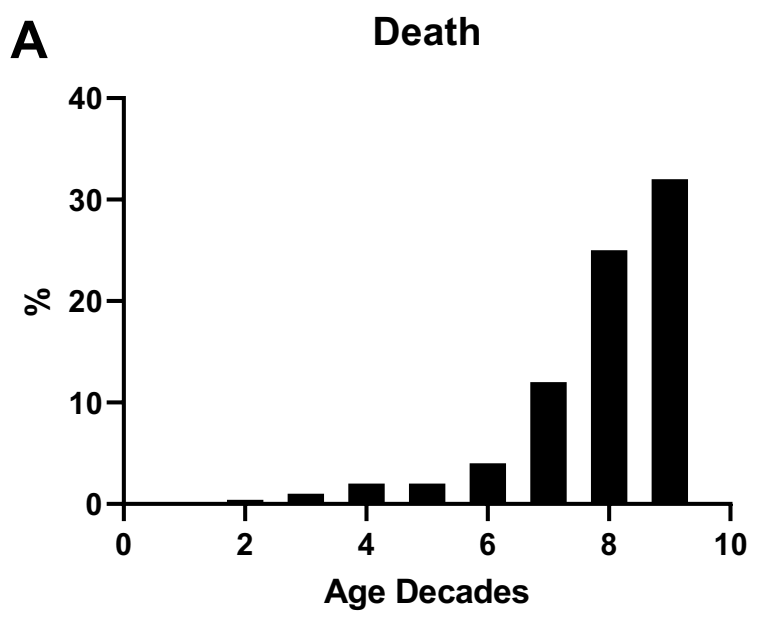

B

ICU access

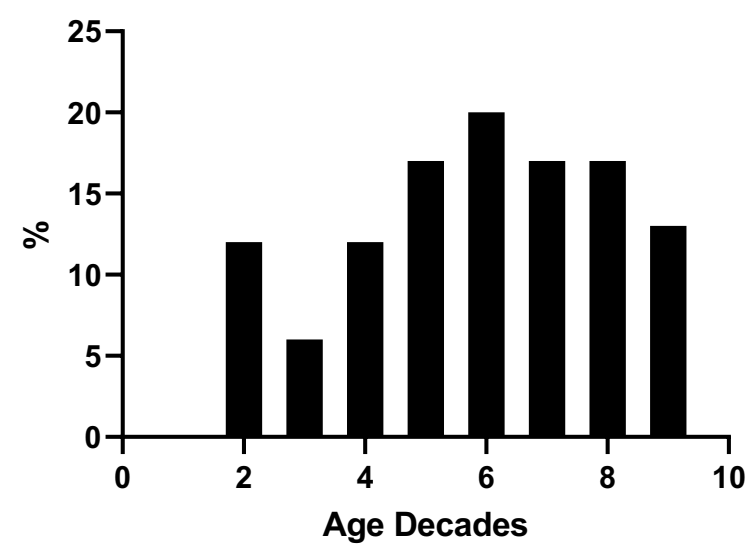

C

Healed

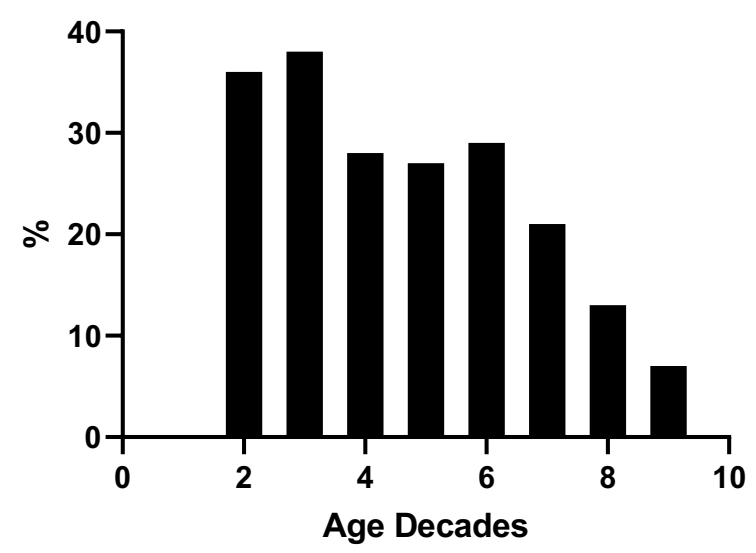

Fig. 1 a Population of the SARS-RAS study (2467 patients) were divided by age decades. The rate of death at each age decade is depicted. b Population of the SARS-RAS study (2467 patients) were divided by age decades. The rate of ICU admission at each age decade is depicted. c Population of the SARS-RAS study (2467 patients) were divided by age decades. The rate of healed patients at the time of the collection of questionnaires at each age decade is depicted.
[24]. Interestingly, our results have been confirmed in the overall COVID-19 population [25]. Indeed, also in other countries, sex differences in morbidity and mortality related to COVID-19 infection have been demonstrated in different clinical scenarios [26]. Recent findings have revealed key differences in immune responses during the disease course of SARS-CoV-2 infection in male and female patients which may help to understand sex differences in COVID-19 infections [27]. Obesity is the most frequent comorbidity observed among those admitted to ICU within both genders while chronic kidney disease and hypertension among men and heart failure among women are associated with a higher rate of ICU admission. Obesity is a well-known cause of respiratory failure which might make these groups of patients at risk of a more severe clinical course if they contract COVID19. Different epidemiological studies have highlighted that obese subjects are potentially more vulnerable to become infected with COVID-19 and have a higher risk for morbidity and mortality among COVID-19 patients [28].

\section{Determinants of Healing Among COVID-19 Patients}

Healing from COVID-19 infection was reported in $22.2 \%$ of patients at the time when the questionnaire was administered. Compared to what was observed in the group of patients that died during the disease, patients who at the time of the collection of the questionnaire were already healed were younger (Fig. 1) and with fewer comorbidities [29]. This observation helps to complete a picture where COVID19 , beyond its inherent morbidity, enhances the burden of multimorbidity in frail patients. COVID-19 represents big stress for the body that results in worse outcomes in the more fragile population. It is therefore possible to speculate that there are treatments that can interfere with patients' fragility and therefore ameliorate their prognosis during COVID-19. Our database allowed us to analyze the possible role of ACEi and ARBs to favor healing in those patients that were assuming that class of drugs. We could not predict any role (either deleterious or protective) of ACEi and ARBs, either alone or as a RAS inhibitors class of drugs [29]. Interestingly, in another collection of Italian patients, it was observed a specific protective effect of ARBs [30]. Therefore, the issue remains still controversial. We are also exploring in the SARS-RAS population the role of other drugs in the settings of the prognosis of the diseases, including the eventual role of oral anticoagulants used for prophylaxis of thromboembolic events in high-risk populations. 


\section{The SARS-RAS 2 Study}

Starting from autumn 2020, infection from COVID-19 had a new upsurge which, however, presents with differences from the previous one. The number of infected has grown, while the number of affected patients who need hospitalization remains low. This observation is probably the result of greater attention towards the early diagnosis of the disease, with a prevalent number of swabs carried out in the asymptomatic population compared to what happened last spring [31].

The epidemiological differences, therefore, imply the need for a new collection of data that highlights the main aspects of the new epidemic of COVID-19 pathology.

This research aims to verify whether the chronic intake of drugs against chronic diseases that increase cardiovascular risk modifies the prevalence and severity of the clinical manifestation of COVID-19. It has been indeed postulated that the basis of the multiple organ failure observed in COVID19 patients resides in the severe endothelial dysfunction, and diffuse thrombotic manifestations [32-34]. The impact of chronically assumed drugs such as statins, oral anticoagulants, and anti-thrombotic agents will be therefore analyzed in the new wave of COVID-19 patients. We will also pay attention to the socio-economic and cultural conditions of COVID-19 patients and their impact on the evolution of the disease.

\section{Clinical Recommendation}

Based on the results of the SARS-RAS study, the Italian Society of Hypertension releases the present recommendations:

- Clinical evidence in humans negates the association of intake of ACE-Is or ARBs and COVID-19 disease. ACE inhibitors and ARBs treatment can be maintained according to the current prescription and based on recommendations contained in the $2018 \mathrm{ESC} / \mathrm{ESH}$ guidelines, and modified only by the prescriber according to the clinical conditions.

- In patients with COVID-19 with severe symptoms or sepsis, ACE Inhibitors and ARBs, like all other antihypertensive drugs, should be used or discontinued on a case by case basis, taking into account current guidelines.

- COVID-19 is an accelerator of death in frail patients, more than a cause of death per se.

- Older, male patients with a large burden of comorbidities are at higher risk of morbidity and mortality from COVID-19 infections. In this specific patient setting spe- cific preventive measures must be adopted to reduce the possibility of infection.

Acknowledgements The SARS-RAS Investigator group is composed of: Arrigo F.G. Cicero 1, Alessandro Grimaldi 25, Alessandro Maloberti 12, Andrea Dalbeni 10, Anna Paini 14, Anna Sabena 5, Antonino Di Guardo 17, Antonio Concistrè 6, Carmine Savoia 2, Carolina De Ciuceis 14, Claudia Agabiti Rosei 14, Claudio Invernizzi 22, Cristiano Fava 10, Davide Fabbricatore 14, Elena Iraca 1, Elisabetta Eula 20, Elvira Fanelli 20, Enzo Grasso 12, Federica De Pisapia 27, Federica Liegi 1, Fernando Chiumiento 21, Flaminia Canichella 18, Fosca Quarti Trevano 22, Francesca Magalini 26, Francesco Salinaro 5, Francesco Spannella 19, Franco Rabbia 20, Franco Cipollini 23, Giovanni Carpani 22, Giulia Molinari 22, Giulia Chiarini 15, Allegra Battistoni 2 Maria Beatrice Musumeci 2 Giuliano Tocci 2, Giuseppe Mulè 4, Luca Bulfone 16, Luigi Pietramala 6, Maddalena Illario 3, Biagio Pinchera 3; Ivan Gentile 3; Anna Guida 29; Maria Chiara Sgariglia 6, Martina Mezzadri 6, Massimo Catanuso 17, Michele Bevilacqua 10, Michele Bombelli 22, Lia Salvati 25, Francesco Carubbi 25, Paolo Carducci 25, Alessandro Grimaldi 25, Paola Vertolli 25, Davide Grassi 25, Rinalda Mariani 25, Sandro Cinotti 25, Franco Tonello 25, Monica Rocco 2, Ornella Piazza 8, Paola Pellimassi 2, Paola Schiavi 19, Paolo Mulatero 20, Paolo Malerba 15, Pierluigi Viale 1, Raffaella Dell'Oro 22, Roberta Mussinelli 5, Roberto Ervo 11, Roberto Pontremoli 24, Roberto Alberto De Blasi 2, Rosario Cianci 6, Santo Di Lorenzo 2, Sara Tedeschi 1, Valeria Bisogni 9 and the COVID19 Niguarda group. The SARS-RAS centers are the following: (1) AO Policlinico Sant'OrsolaMalpighi, Bologna; (2) AOU Sant'Andrea, Roma; (3) AOU Federico II, Napoli; (4) AOU Policlinico Paolo Giaccone, Palermo; (5) AOU Policlinico San Matteo, Pavia; (6) AOU Policlinico Umberto I, Roma; (7) AOU Policlinico Universitario, Padova; (8) AOU San Giovanni di Dio e Ruggi d'Aragona, PO "Dell'Olmo" Cava de' Tirreni; (9) AOU Santa Maria, Terni; (10) AOUI Verona, Italy; (11) ASL 1 Imperiese, Ventimiglia; (12) ASST Grande Ospedale Metropolitano Niguarda, Milano; (13) ASST Santi Paolo e Carlo, Milano; (14) University of Brescia \& ASST SPEDALI CIVILI BRESCIA; (15) University of Brescia \& ASST SPEDALI CIVILI. PO Montichiari; (16) ASUI Friuli Centrale, Udine; (17) Centro Ipertensione Mascalucia, Catania; (18) INMI Lazzaro Spallanzani, Roma; (19) INRCA, Ancona, Italy; (20) Ospedale "Le Molinette", Torino; (21) Ospedale di Eboli, Salerno; (22) Ospedale San Gerardo, Monza; (23) Ospedale San Jacopo, Pistoia; (24) Ospedale San Martino, Genova; (25) PO San Salvatore, L'Aquila and Ospedale di Avezzano, AQ; (26) Ospedale Maggiore, Parma; (27) PO Santissima Trinità, Cagliari; (28) Ospedale NIGUARDA, Milano; (29) Ospedale del Mare, Napoli.

\section{Declarations}

Funding Open access funding provided by Università degli Studi di Napoli Federico II within the CRUI-CARE Agreement.

Conflict of interest On behalf of all authors, the corresponding author states that there is no conflict of interest.

Open Access This article is licensed under a Creative Commons Attribution-NonCommercial 4.0 International License, which permits any non-commercial use, sharing, adaptation, distribution and reproduction in any medium or format, as long as you give appropriate credit to the original author(s) and the source, provide a link to the Creative Commons licence, and indicate if changes were made. The images or other third party material in this article are included in the article's Creative Commons licence, unless indicated otherwise in a credit line to the 
material. If material is not included in the article's Creative Commons licence and your intended use is not permitted by statutory regulation or exceeds the permitted use, you will need to obtain permission directly from the copyright holder. To view a copy of this licence, visit http://creativecommons.org/licenses/by-nc/4.0/.

\section{References}

1. Bourgonje AR, Abdulle AE, Timens W, Hillebrands JL, Navis GJ, Gordijn SJ, et al. Angiotensin-converting enzyme 2 (ACE2), SARS-CoV-2 and the pathophysiology of coronavirus disease 2019 (COVID-19). J Pathol. 2020;251:228-48.

2. Fang L, Karakiulakis G, Roth M. Are patients with hypertension and diabetes mellitus at increased risk for COVID-19 infection? Lancet Respir Med. 2020;8:e21.

3. Iaccarino G, Borghi C, Cicero AFG, Ferri C, Minuz P, Muiesan $\mathrm{ML}$, et al. Renin-angiotensin system inhibition in cardiovascular patients at the time of COVID19: much ado for nothing? A statement of activity from the directors of the board and the scientific directors of the italian society of hypertension. High Blood Press Cardiovasc Prev. 2020;27:105-8.

4. Volpe M, Battistoni A, Board of the Italian Society of Cardiovascular P, Bellotti P, Bellone S, Bertolotti M, et al. Recommendations for cardiovascular prevention during the Sars-Cov-2 pandemic: an executive document by the board of the Italian Society of Cardiovascular Prevention. High Blood Press Cardiovasc Prev. 2020;27:373-7.

5. WHO. Clinical management of severe acute respiratory infection when novel coronavirus (nCoV) infection is suspected: interim guidance. In: Organization. WH editor. https://www.who.int/ publications-detail/clinical-management-of-severeacute-respi ratory-infection-when-novelcoronavirus-(ncov)-infection-is-suspe cted.2020. Accessed 28 Jan 2020.

6. Wu Z, McGoogan JM. Characteristics of and important lessons from the coronavirus disease 2019 (COVID-19) outbreak in China: summary of a report of 72314 cases from the Chinese Center for Disease Control and Prevention. JAMA. 2020;323(13):1239-42.

7. Huang C, Wang Y, Li X, Ren L, Zhao J, Hu Y, et al. Clinical features of patients infected with 2019 novel coronavirus in Wuhan, China. Lancet. 2020;395:497-506.

8. Vaduganathan M, Vardeny O, Michel T, McMurray JJV, Pfeffer MA, Solomon SD. Renin-angiotensin-aldosterone system inhibitors in patients with Covid-19. N Engl J Med. 2020;382:1653-9.

9. Kuba K, Imai Y, Rao S, Gao H, Guo F, Guan B, et al. A crucial role of angiotensin converting enzyme 2 (ACE2) in SARS coronavirus-induced lung injury. Nat Med. 2005;11:875-9.

10. He X, Han B, Mura M, Xia S, Wang S, Ma T, et al. Angiotensinconverting enzyme inhibitor captopril prevents oleic acid-induced severe acute lung injury in rats. Shock. 2007;28:106-11.

11. Volpe M, Battistoni A. Systematic review of the role of reninangiotensin system inhibitors in late studies on Covid-19: a new challenge overcome? Int J Cardiol. 2020;321:150-4.

12. de Simone G, Mancusi C. Speculation is not evidence: antihypertensive therapy and COVID-19. Eur Heart J Cardiovasc Pharmacother. 2020;6:133-4.

13. Iaccarino G, Grassi G, Borghi C, Ferri C, Salvetti M, Volpe M, et al. Age and multimorbidity predict death among COVID-19 patients: results of the SARS-RAS study of the Italian Society of Hypertension. Hypertension. 2020;76:366-72.

14. Reynolds HR, Adhikari S, Pulgarin C, Troxel AB, Iturrate E, Johnson SB, et al. Renin-angiotensin-aldosterone system inhibitors and risk of Covid-19. N Engl J Med. 2020;382:2441-8.
15. Mancia G, Rea F, Ludergnani M, Apolone G, Corrao G. Reninangiotensin-aldosterone system blockers and the risk of Covid- 19 . N Engl J Med. 2020;382:2431-40.

16. Li J, Wang X, Chen J, Zhang H, Deng A. Association of Reninangiotensin system inhibitors with severity or risk of death in patients with hypertension hospitalized for coronavirus disease 2019 (COVID-19) infection in Wuhan, China. JAMA Cardiol. 2020;5:825-30.

17. Meng J, Xiao G, Zhang J, He X, Ou M, Bi J, et al. Reninangiotensin system inhibitors improve the clinical outcomes of COVID-19 patients with hypertension. Emerg Microbes Infect. 2020;9:757-60.

18. Negreira-Caamano M, Piqueras-Flores J, Martinez-DelRio J, Nieto-Sandoval-Martin-DeLaSierra P, Aguila-Gordo D, MateoGomez C, et al. Impact of treatment with renin-angiotensin system inhibitors on clinical outcomes in hypertensive patients hospitalized with COVID-19. High Blood Press Cardiovasc Prev. 2020;27:561-8.

19. Ioannou GN, Locke E, Green P, Berry K, O'Hare AM, Shah JA, et al. Risk factors for hospitalization, mechanical ventilation, or death among 10131 US veterans with SARS-CoV-2 infection. JAMA Netw Open. 2020;3:e2022310.

20. Bello-Chavolla OY, Bahena-Lopez JP, Antonio-Villa NE, VargasVazquez A, Gonzalez-Diaz A, Marquez-Salinas A, et al. Predicting mortality due to SARS-CoV-2: a mechanistic score relating obesity and diabetes to COVID-19 outcomes in Mexico. J Clin Endocrinol Metab. 2020;105:dgaa346.

21. Price-Haywood EG, Burton J, Fort D, Seoane L. Hospitalization and mortality among black patients and white patients with Covid19. N Engl J Med. 2020;382:2534-43.

22. Hewitt J, Carter B, Vilches-Moraga A, Quinn TJ, Braude P, Verduri A, et al. The effect of frailty on survival in patients with COVID-19 (COPE): a multicentre, European, observational cohort study. Lancet Public Health. 2020;5:e444-51.

23. Abate SM, Ahmed Ali S, Mantfardo B, Basu B. Rate of intensive care unit admission and outcomes among patients with coronavirus: a systematic review and meta-analysis. PLoS ONE. 2020;15:e0235653.

24. Iaccarino G, Grassi G, Borghi C, Carugo S, Fallo F, Ferri C, et al. Gender differences in predictors of intensive care units admission among COVID-19 patients: the results of the SARSRAS study of the Italian Society of Hypertension. PLoS ONE. 2020;15:e0237297.

25. Raparelli V, Palmieri L, Canevelli M, Pricci F, Unim B, Lo Noce $\mathrm{C}$, et al. Sex differences in clinical phenotype and transitions of care among individuals dying of COVID-19 in Italy. Biol Sex Differ. 2020;11:57.

26. Suleyman G, Fadel RA, Malette KM, Hammond C, Abdulla H, Entz A, et al. Clinical characteristics and morbidity associated with coronavirus disease 2019 in a series of patients in metropolitan detroit. JAMA Netw Open. 2020;3:e2012270.

27. Takahashi T, Ellingson MK, Wong P, Israelow B, Lucas C, Klein J, et al. Sex differences in immune responses that underlie COVID-19 disease outcomes. Nature. 2020;588:315-20.

28. Albashir AAD. The potential impacts of obesity on COVID-19. Clin Med. 2020;20:e109-13.

29. Mancusi C, Grassi G, Borghi C, Stefano C, Fallo F, Ferri C, et al. Determinants of healing among patients with COVID-19: the results of the SARS-RAS study of the Italian Society of Hypertension. J Hypertens. 2021;39(2):376-80.

30. Palazzuoli A, Mancone M, De Ferrari GM, Forleo G, Secco GG, Ruocco GM, et al. Antecedent administration of angiotensin converting enzyme inhibitors or angiotensin II receptor antagonists and survival after hospitalization for SARS-CoV-2 (COVID-19). J Am Heart Assoc. 2020;9:e017364. 
31. de Simone G, Mancusi C. COVID-19: timing is important. Eur J Intern Med. 2020;77:134-5.

32. Sardu C, Gambardella J, Morelli MB, Wang X, Marfella R, Santulli G. Hypertension, thrombosis, kidney failure, and diabetes: is COVID-19 an endothelial disease? A comprehensive evaluation of clinical and basic evidence. J Clin Med. 2020;9:1417.
33. Libby P, Luscher T. COVID-19 is, in the end, an endothelial disease. Eur Heart J. 2020;41:3038-44.

34. Lowenstein CJ, Solomon SD. Severe COVID-19 is a microvascular disease. Circulation. 2020;142:1609-11. 